\title{
Upper gastrointestinal series in children: what surgeons need to know
}

\author{
Eman Ahmed Hamed', Shaimaa Abdelsattar Mohammad ${ }^{1,2^{*}}$ (D), Leila M. Rawash Eldieb ${ }^{1}$ and \\ Mennatallah Hatem Shalaby'
}

\begin{abstract}
Background: Upper gastrointestinal (UGI) series is the standard imaging tool for diagnosis of structural and functional abnormalities affecting the esophagus, stomach, and proximal small bowel. The aim of this study was to delineate the clinical indications for UGI series in children that are associated with the presence of significant radiological abnormalities aiming for more standardized care for those patients.

Results: UGI series of 118 patients was analyzed with calculation of clinical score. Vomiting was the most frequent primary complaint (63.6\%), followed by dysphagia and recurrent chest infection. Forty-nine patients had positive upper $\mathrm{Gl}$ findings (42\%). The most detected abnormality was related to the stomach and duodenum (21.4\%). Variable degrees of idiopathic gastroesophageal reflux were detected in 16 patients (13.6\%). Patients with clinical score 2 or more had significantly more prevalence of abnormal findings $(p=.001)$. Vomiting (especially when bilious), underweight, aspiration, and recurrent chest infection were strong predictors of abnormal findings on upper Gl series ( $p=0.007,0.001,0.009$, and 0.001 , respectively) and increased the diagnostic yield of upper Gl series for detection of abnormalities by $3.48,9.6,4$, and 4.12 times, respectively.
\end{abstract}

Conclusion: Diagnostic yield of UGI series was relatively higher in patients having two or more symptoms (clinical score 2 or more) and in children with bilious vomiting, aspiration and underweight, or repeated chest infection.

Keywords: Diagnostic yield, Vomiting, Dysphagia, Gastroesophageal reflux, Chest infection

\section{Background}

Upper gastrointestinal (UGI) series is frequently performed in the pediatric radiology department. It is considered the standard imaging tool for diagnosis of structural and functional abnormalities implicating the esophagus, stomach, and proximal small bowel. It perfectly demonstrates congenital malformations affecting the gastrointestinal tract (e.g., hiatus hernia, intestinal malrotation); in addition, it can depict extra-luminal esophageal compression by an anomalous blood vessel or an external compressing mass. Underlying causes of

\footnotetext{
* Correspondence: shaimaa96@hotmail.com

'Department of Radiodiagnosis, Faculty of Medicine, Ain-Shams University, Ramsis St., Abbasia, Cairo, Egypt

${ }^{2}$ Department of Radiodiagnosis, Faculty of Medicine, Ain-Shams University, 9 Ain-Shams University Staff Buildings, Lotfi Elsayed St, Cairo 11657, Egypt
}

dysmotility disorders such as achalasia are also properly evaluated [1-3].

In clinical practice, UGI series is usually performed in many children with symptoms related to the gastrointestinal tracts, particularly vomiting, dysphagia, or abdominal pain. However, unindicated radiological procedure could unnecessarily expose more sensitive patients in the pediatric age group to the detrimental effects of ionizing radiation $[4,5]$. Moreover, in view of limited resources and emphasis on quality and safety of radiologic procedures, the risk versus potential benefits should be weighed before proceeding with any procedure.

The diagnostic value of UGI series is explored in a few papers in the literature especially focusing on children with vomiting $[2,6-8]$. Consequently, there is a remarkable need to evaluate its usefulness in the clinical management of those patients.

\section{Springer Open}

(-) The Author(s). 2020 Open Access This article is licensed under a Creative Commons Attribution 4.0 International License which permits use, sharing, adaptation, distribution and reproduction in any medium or format, as long as you give appropriate credit to the original author(s) and the source, provide a link to the Creative Commons licence, and indicate if changes were made. The images or other third party material in this article are included in the article's Creative Commons licence, unless indicated otherwise in a credit line to the material. If material is not included in the article's Creative Commons licence and your intended use is not permitted by statutory regulation or exceeds the permitted use, you will need to obtain permission directly from the copyright holder. To view a copy of this licence, visit http://creativecommons.org/licenses/by/4.0/. 
The aim of this study was to obviously delineate the clinical indications for UGI series in children and their association with the presence of significant radiological abnormalities aiming for more standardized care for those patients.

\section{Methods}

\section{Patient selection}

After ethical and internal review board approval, a cross-sectional study was conducted at the radiology unit in our university pediatric hospital. All patients presented to our unit requesting UGI series were initially included in the study; patients with history of corrosive ingestion or prior UGI surgeries were excluded. Patients with incomplete studies or insufficient clinical data were also excluded. Informed oral consent including all procedure details was obtained from all parents or guardians before the procedure.

All patients were subjected to detailed history taking and were instructed to fast for 4 to $6 \mathrm{~h}$ before the procedure. Figure 1 refers to history taking sheet adopted in our department.

\section{Procedure detail}

UGI series was performed by using TOSHIBA ZEXIRA DRX (MODEL BLF-15B) for pulse fluoroscopy with last screen capture at a rate 3-4 frames/s. Anteroposterior scout film is obtained. Imaging started from the oropharynx to the duodenojejunal flexure using single contrast technique. The contrast is administered by bottle or through a nasogastric tube. AP and lateral views of the esophagus are obtained. Lateral view of the duodenum is then obtained while the contrast passes through its second part. This is followed by AP view of the duodenojejunal flexure. Finally, an AP image was obtained once the contrast had passed into the jejunum. No specific maneuvers or tests were performed to initiate reflux $[9,10]$.

\section{Data collection}

Age, gender, and the primary complaint for each patient are recorded, and all radiologic abnormalities were documented.

\begin{tabular}{|c|c|}
\hline \multicolumn{2}{|l|}{$\begin{array}{l}\text { Name: } \\
\text { Gender: } \\
\text { Age: }\end{array}$} \\
\hline \multicolumn{2}{|c|}{$\begin{array}{l}\text { Type of the study: } \\
\text { Contrast used and its concentration: }\end{array}$} \\
\hline \multicolumn{2}{|l|}{ Complaint: } \\
\hline Vomiting & -Bilious/Non bilious \\
\hline Aspiration & Yes/No \\
\hline $\begin{array}{l}\text { Repeated respiratory related } \\
\text { symptoms }\end{array}$ & Yes/No \\
\hline Dysphagia & $\begin{array}{l}\text { Yes/No } \\
\text { If yes, site (upper or lower): } \\
\text { More with fluids or solids: }\end{array}$ \\
\hline Abdominal pain & Yes/No \\
\hline Change in bowel habits & $\begin{array}{l}\text { Yes/No } \\
\text { If yes, the current bowel habit: }\end{array}$ \\
\hline Hematemesis & Yes/No \\
\hline $\begin{array}{l}\text { Presence of melena or } \\
\text { blood in stool }\end{array}$ & Yes/No \\
\hline Other symptoms & \\
\hline Medical history & \\
\hline Surgical history & \\
\hline
\end{tabular}

Fig. 1 Patient's history sheet 


\section{Predictor variable}

The indication for UGI series was determined based on patients' symptoms. Indications include vomiting, dysphagia, underweight, aspiration, recurrent chest infection, abdominal pain, change in bowel habits, hematemesis, or melena. As patients might have more than one symptom, a clinical score was calculated for each patient setting 1 point for each symptom as we have recently published [8]. The total number of patients having each symptom as isolated or in association was also calculated.

\section{Outcome variables}

The UGI series findings were categorized into normal and abnormal groups where the latter group includes all positive UGI series. The abnormal group was further divided into 4 groups according to the location of the dominant abnormal findings: patients with idiopathic gastroesophageal reflux (GER), patients with findings related to the esophagus, patients with findings related to both stomach and duodenum, and lastly aspiration. The groups of patients with normal and abnormal findings were compared regarding their clinical scores.

\section{Statistical analysis}

Different groups were compared regarding patients' age and gender. They were also analyzed regarding their clinical presentation (vomiting, dysphagia, underweight, aspiration, recurrent chest infection, abdominal pain, change in bowel habit, hematemesis, and melena). Multinomial logistic regression models were built to assess confounding variables and relevant interactions, using backward stepwise regression to determine independent predictors for positive upper GI findings

Numeric variables were provided as the median (IQR) and range. The Kruskal-Wallis $H$ test was used to compare continuous variables and the chi-square test to compare categorical variables. A probability value ( $p$ value) less than 0.05 was considered statistically significant. $\mathrm{IBM}^{\circ} \mathrm{SPSS}^{\circ}$ Statistics 21 version was used for statistical analysis.

\section{Results}

One hundred and eighteen patients (out of 320 patients who underwent upper GI series) were included in the study. The remaining patients were excluded due to one or more of the previously mentioned exclusion criteria.

Patients ranged in age from 5 days to 17 years (median 2 years). Table 1 summarizes the patients and findings of their UGI series according to their primary complaint. Vomiting was the most frequently encountered symptom $(n=85 ; 72.6 \%)$, and it was non-bilious in 79 patients; however, it was the primary complaint in 75 patients. Thirty-five patients reported recurrent chest infection (30\%), and it was the primary complaint in only 11 patients. Dysphagia was reported by 18 patients $(15.4 \%)$, and it was the primary complaint in 13 patients. Seventeen patients had a history of aspiration, and it was the primary complaint in 9. Additionally, underweight was present in 72 patients (61.5\%), abdominal pain was present in 30, changes in bowel habits was reported in

Table 1 UGl series findings in relation to patients' symptoms

\begin{tabular}{|c|c|c|c|c|c|c|}
\hline \multirow{2}{*}{$\begin{array}{l}\text { Primary } \\
\text { complaint } \\
\text { (number } \\
\text { of } \\
\text { patients*) }\end{array}$} & \multirow{2}{*}{$\begin{array}{l}\text { Findings when } \\
\text { isolated }\end{array}$} & \multicolumn{5}{|c|}{ Findings when combined with other symptoms } \\
\hline & & $\begin{array}{l}\text { Normal } \\
\text { study }\end{array}$ & $\begin{array}{l}\text { Idiopathic } \\
\text { GER }\end{array}$ & $\begin{array}{l}\text { Esophageal or } \\
\text { oropharyngeal } \\
\text { abnormalities }\end{array}$ & Gastric abnormalities & Duodenal abnormalities*** \\
\hline $\begin{array}{l}\text { Vomiting } \\
(75)^{* *}\end{array}$ & $\begin{array}{l}\text { Normal (13), GER } \\
\text { (1), pyloric } \\
\text { obstruction with } \\
\text { gastritis (1) }\end{array}$ & 23 & 15 & $\begin{array}{l}\text { Peptic stricture } \\
(1)\end{array}$ & $\begin{array}{l}\text { Pyloric obstruction (2), IHPS (2), } \\
\text { gastritis ( } 2) \text {, hiatus hernia ( } 4) \text {, hiatus } \\
\text { hernia with gastric volvulus (1), } \\
\text { primary gastric volvulus (3) }\end{array}$ & $\begin{array}{l}\text { Duodenal atresia (1), midgut } \\
\text { malrotation (3), midgut } \\
\text { malrotation with midgut volvulus } \\
\text { (1), SMA syndrome (1) }\end{array}$ \\
\hline $\begin{array}{l}\text { Dysphagia } \\
(13)\end{array}$ & Normal (5) & 6 & 0 & $\begin{array}{l}\text { Achalasia } \\
\text { secondary to } \\
\text { mediastinal } \\
\text { lymphoma (1) }\end{array}$ & Gastritis (1) & \\
\hline $\begin{array}{l}\text { Recurrent } \\
\text { chest } \\
\text { infection } \\
\text { (11) }\end{array}$ & Normal (3) & 5 & 0 & $\begin{array}{l}\text { False passage of } \\
\text { the esophagus } \\
\text { (1) }\end{array}$ & $\begin{array}{l}\text { Diaphragmatic hernia and volvulus of } \\
\text { the stomach (1) }\end{array}$ & $\begin{array}{l}\text { Midgut malrotation with gastric } \\
\text { volvulus (1) }\end{array}$ \\
\hline $\begin{array}{l}\text { Aspiration } \\
\text { (9) }\end{array}$ & Normal (1) & 3 & 0 & $\begin{array}{l}\text { Oropharyngeal } \\
\text { aspiration (5) }\end{array}$ & 0 & 0 \\
\hline
\end{tabular}

GER gastroesophageal reflux, IHPS infantile hypertrophic pyloric stenosis, SMA superior mesenteric artery syndrome

*The number of patients was calculated according to the primary complaint

**Additional one case with Alport syndrome (with midgut malrotation, combined hiatus hernia, diffuse esophageal leiomyomatosis) was complaining of vomiting epigastric pain and dysphagia.

${ }^{* * *}$ All patients with duodenal abnormalities presented with attacks of bilious vomiting 

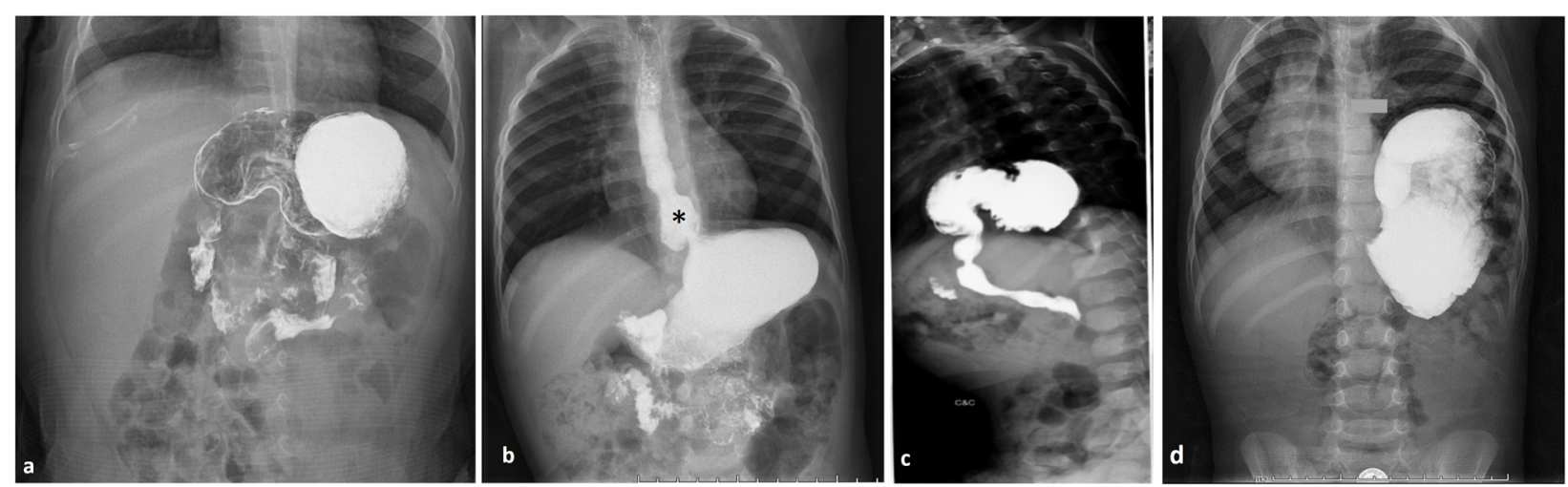

Fig. 2 Different patterns of gastric abnormalities. a Gastric organoaxial volvulus. b Sliding hiatus hernia (asterisk) with dilated esophagus. c Large hiatus hernia containing most of the stomach associated with volvulus. $\mathbf{d}$ Left-sided Bochdalek hernia containing the stomach and other bowel loops

14, and attacks of melena was present in 9 while hematemesis was present in 8 .

Forty-nine patients had positive UGI findings (42\%). The most detected abnormality was related to the stomach and duodenum (25 patients, 21.4\%) (Figs. 2, 3, and 4). Variable degrees of idiopathic gastroesophageal reflux were detected in 16 patients (13.6\%) (Fig. 5). Five patients were found to have aspiration (4.3\%), and four patients had findings related to the esophagus (Figs. 6 and 7). Table 1 summarizes the detected abnormalities in relation to patients' symptoms.
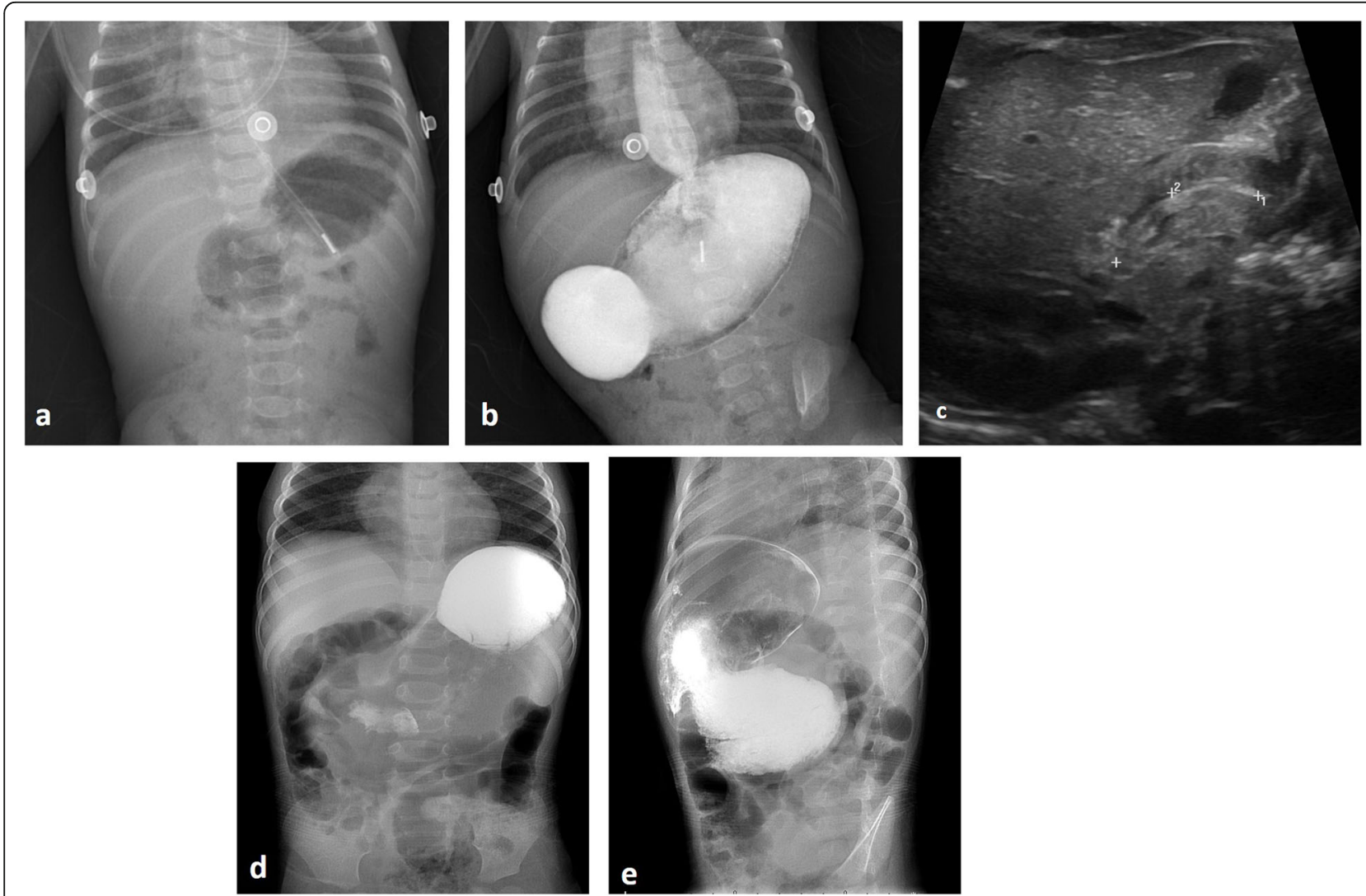

Fig. 3 Two different patients with pyloric obstruction. Upper row neonate with infantile hypertrophic pyloric stenosis. a Plain AP view shows stomach with wave-like contour (caterpillar sign) and paucity of distal abdominal gas. b AP view shows distended stomach with delayed gastric emptying. c Ultrasound scan showing elongated and thickened pyloric canal. d, e Patient with idiopathic acquired gastric outlet obstruction. $\mathbf{d}$ AP view shows dilated stomach displacing the surrounding bowel loops. e Oblique view shows the dilated stomach with delayed gastric emptying 


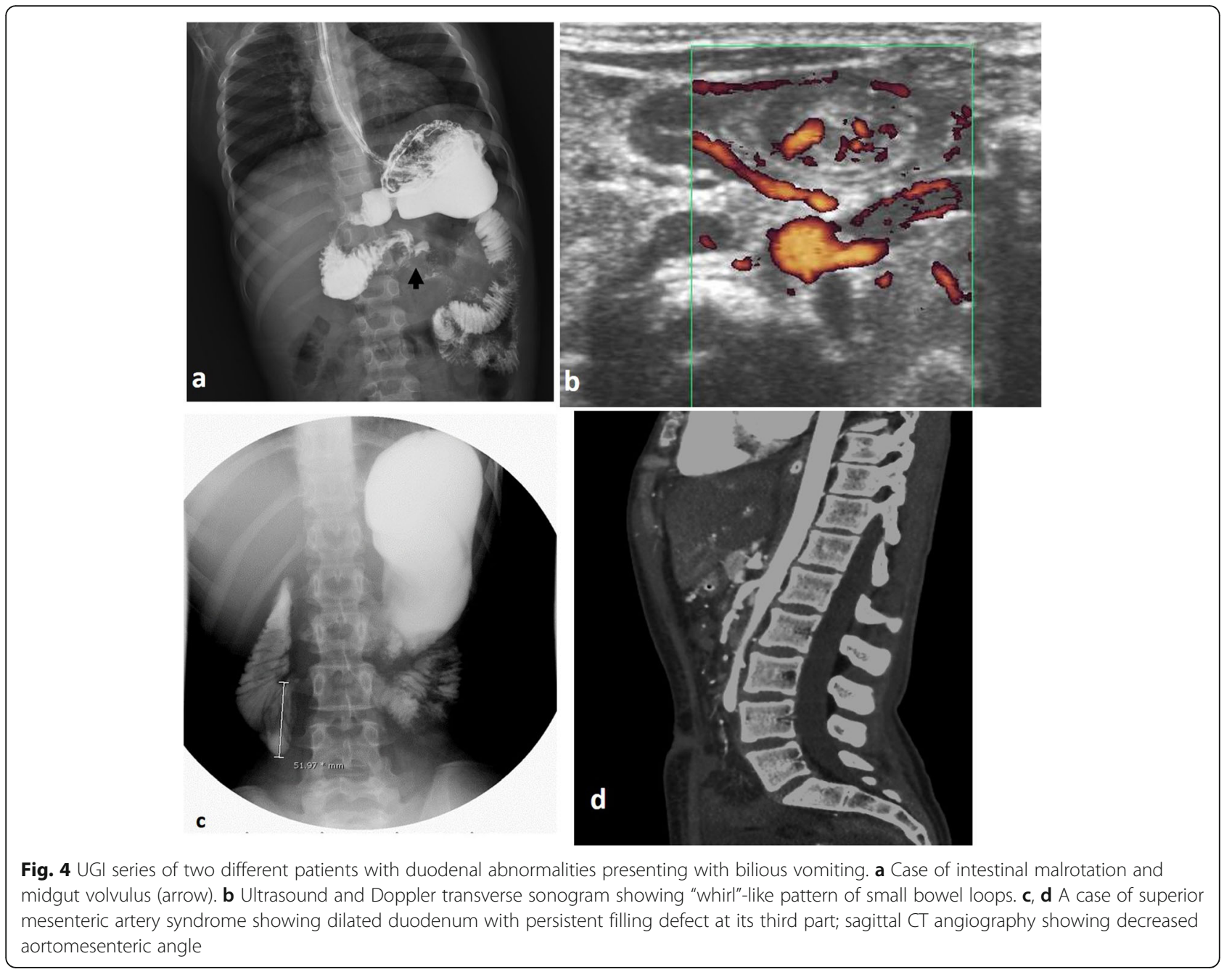

Patients with GER were found to be significantly younger than other groups (median 10 months; range 3-14 months). In addition, GER was found to be the most prevalent abnormality below the age of 6 months. On the contrary, patients with findings related to the esophagus were found to be significantly older than patients with other findings (median 36; range 4-180 months; $p=.04$ ) (Fig. 8). There was no significant
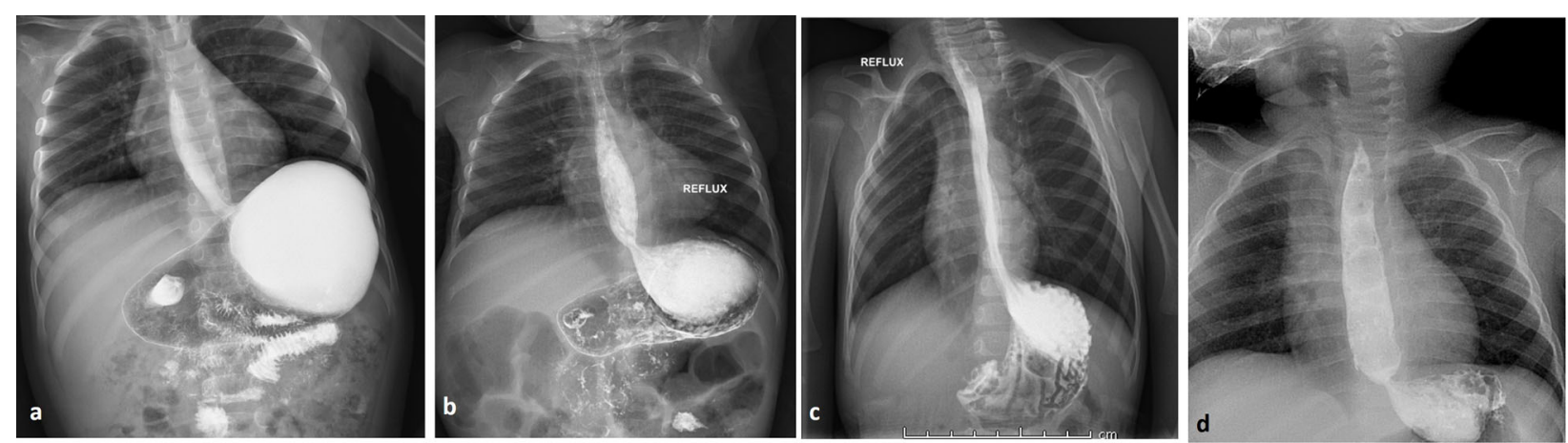

Fig. 5 Different patterns of idiopathic gastroesophageal reflux. a Reflux exceeding the middle third of the esophagus with no luminal dilatation. b Reflux reaching up to the level of mid-esophagus with luminal dilatation. Larger amount of reflux reaching up to the level of upper esophagus without (c) and with luminal dilatation (d) 

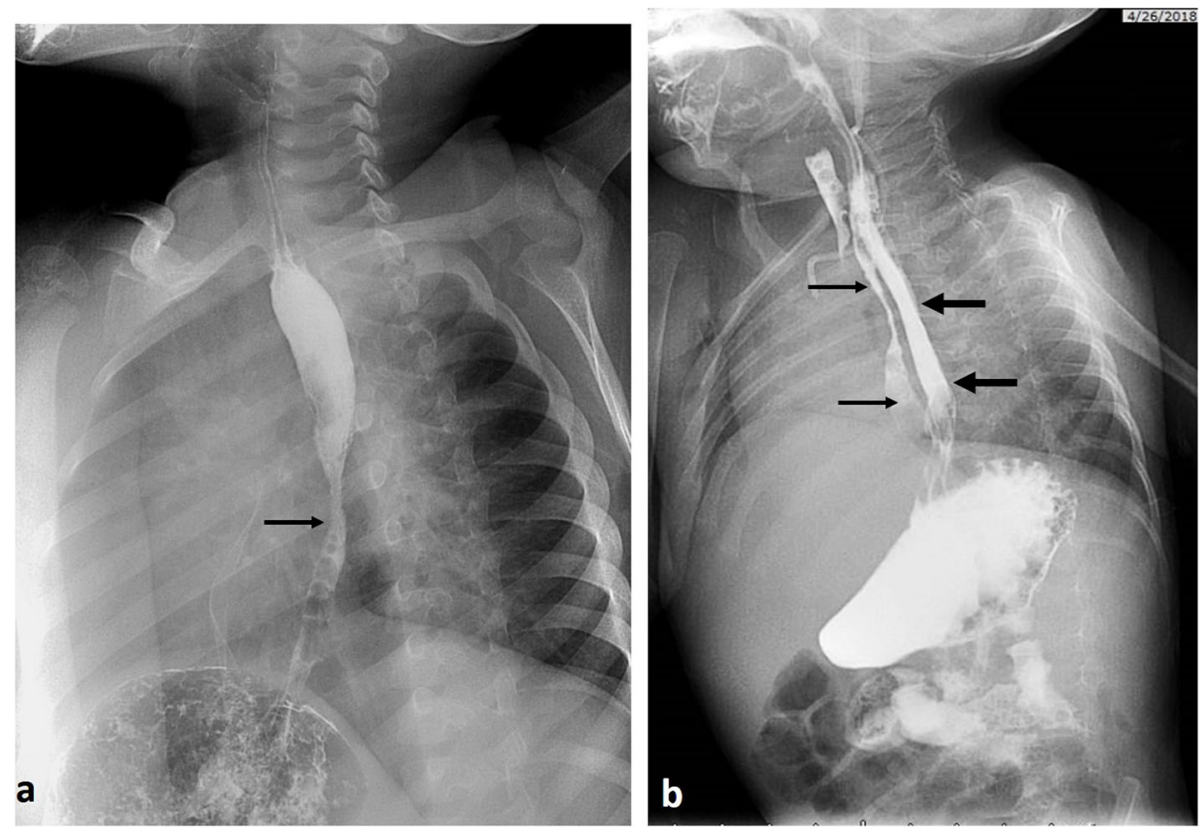

Fig. 6 Two patients with esophageal findings. a A 3-year-old boy complaining of vomiting and dysphagia showing peptic stricture (arrow). b A 3-month-old girl presented with unresolved chest infections since birth and history of suction of secretion at birth; oblique view shows evidence of false passage, evident by the presence of false lumen (thin arrows) with true esophageal lumen (thick arrows)

statistical difference in the incidence of positive or normal UGI series based on patients' gender $(p=.49)$.

The calculated clinical score was significantly low in patients with normal UGI series $(p<.001)$. Among 29 patients with a solitary symptom (scored 1), 27 patients were found to have normal findings. Consequently, patients with clinical score 2 or more had significantly more prevalence of abnormal findings $(p=.001)$ (Fig. 9).

Forty-three patients $(54.4 \%)$ out of 79 patients with non-bilious vomiting had a normal UGI series, and 19 patients (24\%) had findings related to the stomach (Figs. 2 and3). However, all patients presenting with bilious vomiting had abnormal findings (6 patients) related to the duodenum: four patients with midgut malrotation, one of them had associated volvulus; one patient with duodenal atresia; and another one with SMA syndrome (Fig. 4).

Vomiting, underweight, aspiration, and recurrent chest infection were strong predictors of abnormal findings on UGI series $(p=0.007,0.001,0.009$, and 0.001 , respectively) and increased the diagnostic yield of upper GI series for detection of abnormalities by 3.48, 9.6, 4, and 4.12 times, respectively. However, with multivariate analysis, recurrent chest infection did not show significant results (Table 2).

Vomiting was a strong predictor of detection of GER and findings related to the stomach and duodenum on upper GI series $(p=.001)$ as all patients with findings related to the stomach and duodenum and $93.8 \%$ of patients with detected GER on UGI series presented with vomiting. After adjusting other variables, vomiting increased the risk of the finding of GER on UGI series by 8.7 times.

Weight loss or failure to thrive and chest-related symptoms were found to be strong predictors of GER on UGI series $(p=.001)$ as $93.8 \%$ and $62.5 \%$ patients of the GER group had weight loss or failure to thrive, and chest-related symptoms, respectively. After adjusting other variables, weight loss or failure to thrive, and chest-related symptoms increased the risk of finding GERD on UGI series by 20.1 and 7.7 times, respectively.

Dysphagia was a predictor of findings related to the esophagus on upper GI series $(p=.034)$ as two of the four patients of esophageal findings had dysphagia (Figs. 6 and 7). After adjusting other variables, dysphagia increased the risk of esophageal findings on UGI series by 8.4 times.

Aspiration, underweight, and recurrent chest infection were strong predictors of the aspiration group $(p=$ 0.001 ) as all five patients with detected aspiration on UGI series presented with all these symptoms. Two of them had cerebral palsy, and one had neurodegenerative disorders with pseudobulbar palsy and palato-pharyngeal incoordination.

Also, abdominal pain was a strong predictor of findings related to the stomach and duodenum $(p=0.001)$ as $68 \%$ of findings related to the stomach and duodenum belonged to patients presented with abdominal pain. After adjusting other variables, abdominal pain increased 

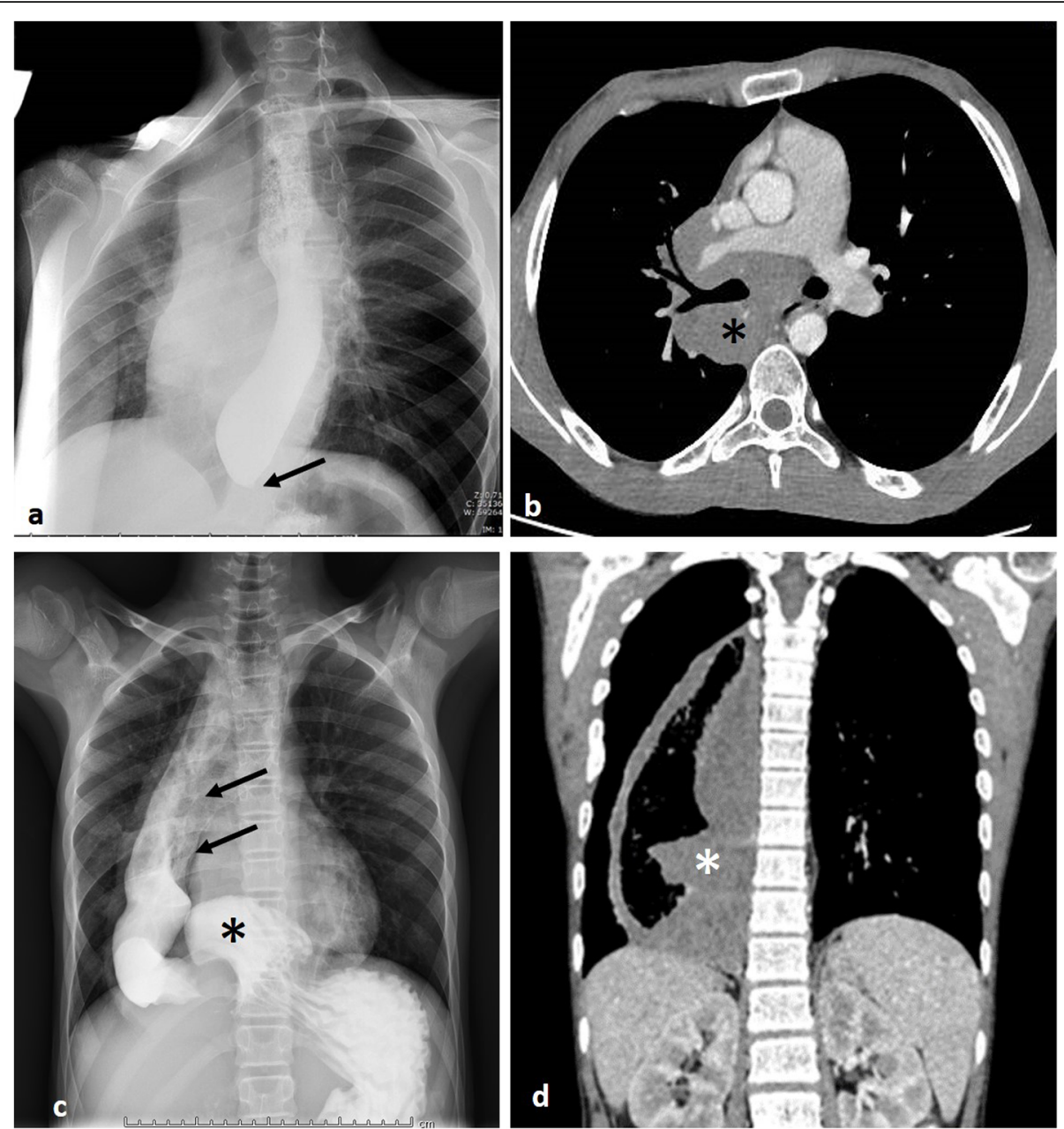

Fig. 7 UGl series of two patients with findings related to the esophagus. a A 15-year-old boy with lymphoma, presented with dysphagia, and significant weight loss, showing esophageal compression by large homogenous opacity and parrot peak appearance of the lower esophagus consistent with achalasia (arrow). b Axial chest CT showing enlarged mediastinal lymph nodes encasing mediastinal structures (asterisk). c A 14-year-old male patient with Alport syndrome presented with vomiting, epigastric pain, and dysphagia; UGI series shows markedly dilated esophagus (arrows) and hiatus hernia (asterisk). d AP shows dilated esophagus with esophageal wall thickening representing leiomyomatosis (asterisk)

the risk of gastric and duodenal findings on UGI series by 8.9 times.

Patients with changes in bowel habits, hematemesis, or melena were found to be linked to gastric findings, but this correlation did not reach a statistically significant value.

\section{Discussion}

The current study analyzed the different radiological findings of UGI series in children in relation to their symptoms. Vomiting was found to be the most common presenting symptom, followed by dysphagia and recurrent chest infection. The majority of abnormal findings were due to underlying gastric and duodenal pathologies (21.4\%) followed by GER (13.6\%). Vomiting and abdominal pain were found to be significantly associated with findings related to the stomach and the duodenum. In addition, we adopted our new clinical score to increase the diagnostic yield of UGI series, so that the impact of clinical symptoms on the findings of the UGI series is objectively assessed [8]. We found that patients with higher clinical scores (especially score 2 or more) were more likely to have abnormal UGI series.

As previously reported, we have found that idiopathic GER was more prevalent in younger children. Moreover, GER was the most prevalent abnormality in infants below the age of 6 months in whom non-bilious vomiting was the primary complaint. The high prevalence of GER is expected in this very young age group, as 70 to $85 \%$ of infants show physiological reflux during their first 60 days of life and it resolves spontaneously without intervention in the first year of life $[6,11,12,17]$. On the contrary, the age of the patients with abnormal esophageal findings was found to be significantly higher 


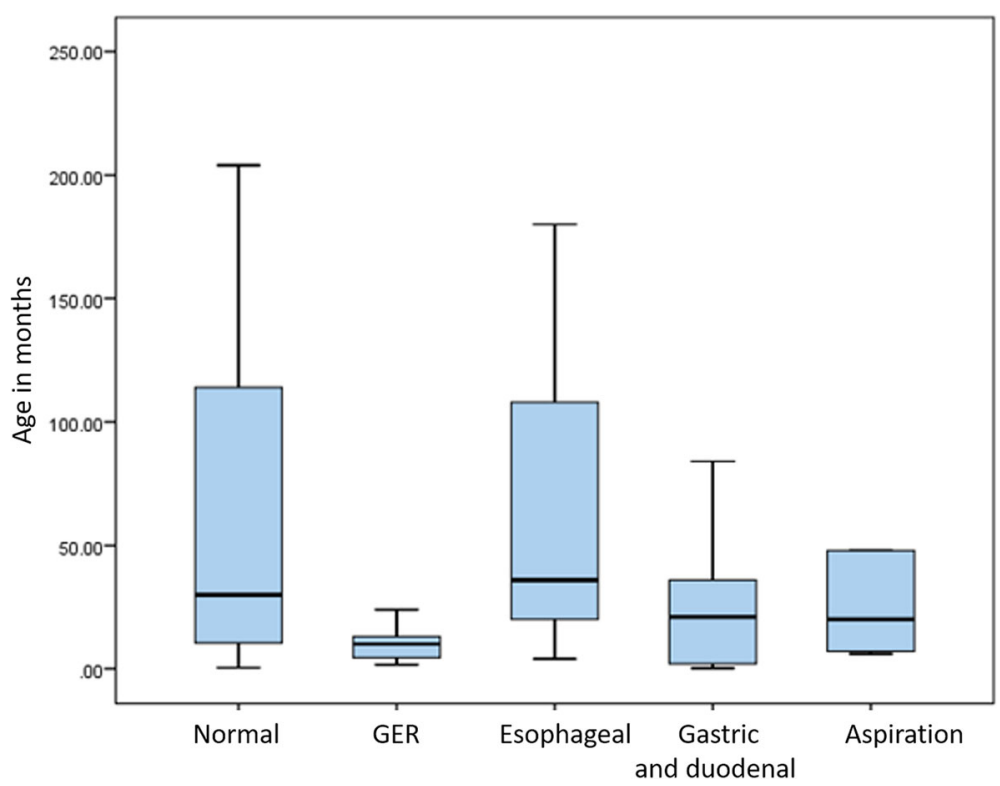

Fig. 8 Age distribution among different study groups

than the age of patients with GER or other positive findings, as previously reported [6]. This is primarily related to the nature of the encountered diseases themselves as peptic stricture occurs after relatively prolonged period of exposure to refluxed acidic gastric content; also, achalasia secondary to lymphoma occurs relatively at an older age. However, in our study, both increasing age and presence of dysphagia did not improve the diagnostic yield of the UGI series. It is likely that expression of dysphagia was used incorrectly by those young patients or their guardians.
Bilious vomiting was found to be a strong significant predictor and improved the diagnostic yield of the upper GI series, as all patients presenting with bilious vomiting showed positive upper GI series findings related to the duodenum (duodenal atresia, midgut malrotation, and superior mesenteric artery syndrome). As previously reported, intestinal malrotation is almost always presented with vomiting characteristically bilious. Although it was reported that intestinal malrotation is classically a disease of infancy [13-15], intestinal malrotation should be suspected in every child with repeated attacks of bilious

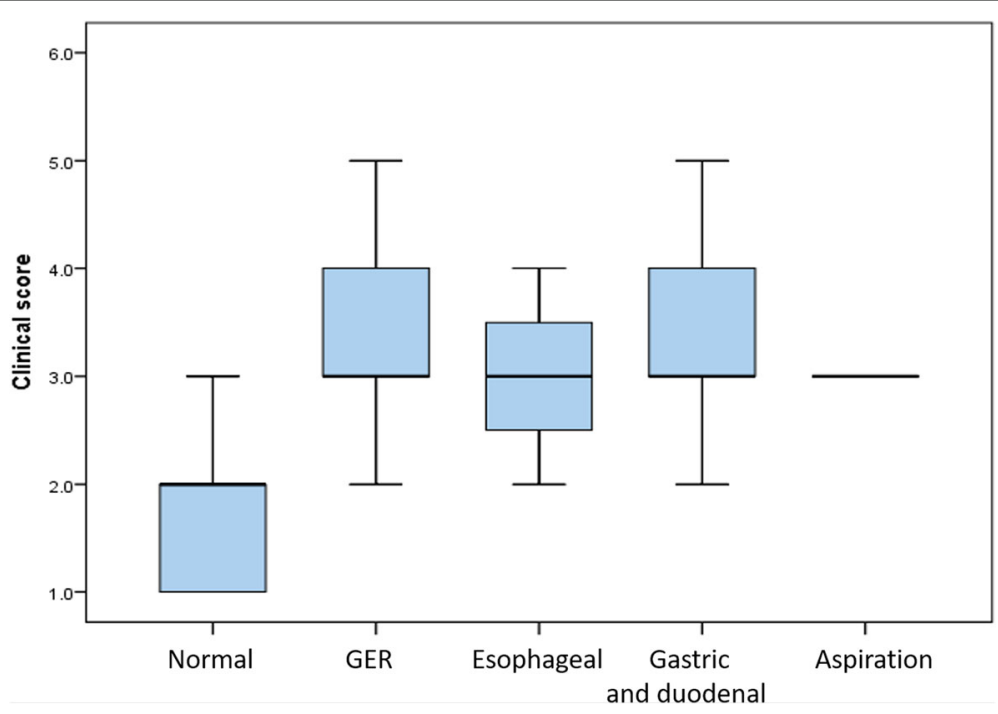

Fig. 9 The calculated clinical score in different study groups 
Table 2 Multinomial logistic regression model assessing independent predictors of upper Gl series outcomes

\begin{tabular}{|c|c|c|c|c|c|c|}
\hline & \multicolumn{3}{|c|}{ Univariate } & \multicolumn{3}{|c|}{ Multivariate } \\
\hline & $p$ value & OR & $95 \% \mathrm{Cl}$ for $\mathrm{OR}$ & $p$ value & OR & $95 \% \mathrm{Cl}$ for $\mathrm{OR}$ \\
\hline Vomiting & 0.009 & 3.488 & $1.363-8.928$ & 0.010 & 5.741 & $1.519-21.692$ \\
\hline Weight loss or failure to thrive & 0.000 & 9.638 & $3.617-25.682$ & 0.001 & 5.876 & $2.05-16.845$ \\
\hline Aspiration & 0.014 & 4.086 & $1.334-12.518$ & 0.047 & 5.346 & $1.023-27.93$ \\
\hline Recurrent chest infection & 0.001 & 4.128 & $1.784-9.550$ & 0.158 & 2.151 & $0.742-6.232$ \\
\hline
\end{tabular}

95\% Cl 95\% confidence interval

vomiting even beyond the neonatal period (median age of cases of intestinal malrotation was 5.5 years).

Spontaneous aspiration was reported to be frequent in children with feeding difficulties and is most likely to occur in children with underlying neurologic disease [16]. In our study, most of the patients with aspiration had cerebral palsy or neurodegenerative disorders with pseudobulbar palsy and palato-pharyngeal incoordination. Our findings revealed that aspiration symptoms were significantly associated with the detection of aspiration on UGI series, and it significantly improved the diagnostic yield of the UGI series especially if associated with repeated attacks of chest infection/symptoms.

Our study could be limited by the heterogenous group of patients' population including all children in the pediatric age group up to 18 years of age, which could make conclusions about certain indications for UGI series difficult. Dividing patients into different age range would be appropriate to study each group individually. Moreover, given the young age of most of the patients, most of their complaints were expressed by their parents or guardians, which might not be totally accurate. However, this is a cross-sectional study that included a relatively large number of children presenting with complaints related to the upper gastrointestinal tract and it represents an experience from a tertiary care center. All patients were submitted to a standardized technique allowing a uniform interpretation of all studies in order to reach comprehensive evaluation of all results. In addition, in view of the complex nature of the presenting symptoms, a clinical score was calculated considering patients' primary complaints and all other associated symptoms in order to study the diagnostic yield of UGI series for those patients with multiple complaints.

\section{Conclusion}

Vomiting, dysphagia, or recurrent chest infection was the most common indication for UGI series. Most radiologic findings were due to gastric and duodenal abnormalities followed by GER. Idiopathic GER was more prevalent in young infants. Diagnostic yield of UGI series was relatively higher in patients having two or more symptoms (clinical score 2 or more) and in children with bilious vomiting, aspiration and underweight, or repeated chest infection.

Abbreviations

GER: Gastroesophageal reflux; UGI: Upper gastrointestinal

\section{Acknowledgements}

Part of this work was presented in ECR 2018 as an electronic poster (educational exhibit). DOI: https://doi.org/10.26044/ecr2019/C-0963.

\section{Authors' contributions}

All authors contributed to the study conception and design. Material preparation, data collection, and analysis were performed by EAH and SAM. The first draft of the manuscript was written by EAH, and all authors read and approved the final manuscript.

Funding

None

Availability of data and materials

The datasets used and/or analyzed during the current study are available from the corresponding author on reasonable request.

\section{Ethics approval and consent to participate}

The study was performed after ethical committee approval in accordance with the ethical standards laid down in the 1964 Declaration of Helsinki and its later amendments. The study was approved by the ethical committee of the Faculty of Medicine, Ain-Shams University. Oral informed consent for participation was given by patients' parent or legal guardian. As the study imposes no additional risk to the participants, the committee's reference number was exempted.

\section{Consent for publication}

Patient identity did not appear in any part of the manuscript; therefore, consent for publication was not required.

\section{Competing interests}

None

Received: 6 June 2020 Accepted: 10 November 2020

Published online: 09 December 2020

\section{References}

1. Khan S, Orenstein S. Embryology, anatomy and function of the esophagus. In: Kliegman R, Stanton B, St Geme J, et al., editors. Nelson Textbook of Pediatrics, vol. 318. 20th ed. Philadelphia: Elsevier; 2016. p. 1781-2.

2. Simanovsky N, Buonom C, Nurko S. The infant with chronic vomiting: the value of the upper GI series. Pediatr Radiol. 2002;32:549-50.

3. Ahmed E, Rawash L, Shalaby M, et al. Role of upper Gl series in children, Electronic Poster ECR. 2019. https://doi.org/10.260/ecr2019/c_0963.

4. Kleinerman RA. Cancer risks following diagnostic and therapeutic radiation exposure in children. Pediatr Radiol. 2006;36(2):121-5.

5. Emigh B, Gordon CL, Connolly BL, et al. Effective dose estimation for pediatric upper gastrointestinal examinations using an anthropomorphic phantom set and metal oxide semiconductor field-effect transistor (MOSFET) technology. Pediatr Radiol. 2013;43:1108-16. 
6. Goldman-Yassen AE, Gross J, Novak I. Identification of clinical parameters to increase the diagnostic yield of the non-emergent upper gastrointestinal series in pediatric outpatients. Pediatr Radiol. 2019;49:162-7.

7. Raske ME, Dempsey ME, Dillman JR, et al. ACR appropriateness criteria vomiting in infants up to 3 months of age. J AmColl Radiol. 2015;12:915-22.

8. Mohammad SA, Hamed EA, Shalaby MH, et al. Upper Gl series in infants and children with vomiting: insights into ACR appropriateness criteria. Egypt J Radiol Nucl Med. 2020;51:166.

9. Donnelly LF Gastrointestinal. In Fundamentals of pediatric imaging, (2017) 2nd Elsevier, Philadelphia, pp 92-130.

10. American College of Radiology (2015) ACR-SPR practice parameter for the performance of contrast esophagrams and upper gastrointestinal examinations in infants and children https://www.acr.org/-/media/ACR/Files/ Practice-Parameters/UpperGI-Infants.pdf. Accessed March 2020.

11. Rosen $R$, Vandenplas $Y$, Singendonk $M$, et al. Pediatric gastroesophageal reflux clinical practice guidelines: joint recommendations of the North American Society for Pediatric Gastroenterology, Hepatology, and Nutrition and the European Society for Pediatric Gastroenterology, Hepatology, and Nutrition. J Pediatr Gastroenterol Nutr. 2018;66:516-54.

12. Leonidas JC. Gastroesophageal reflux in infants: role of the upper gastrointestinal series. AJR Am J Roentgenol. 1984;143:1350-1.

13. Sizemore AW, Rabbani KZ, Ladd A, Applegate KE. Diagnostic performance of the upper gastrointestinal series in the evaluation of children with clinically suspected malrotation. Pediatr Radiol. 2008;38:518-28.

14. Applegate KE, Anderson JM, Klatte EC. Intestinal malrotation in children: a problem-solving approach to the upper gastrointestinal series. Radiographics. 2006;26:1485-500.

15. Lampl B, Levin TL, Berdon WE, et al. Malrotation and midgut volvulus: a historical review and current controversies in diagnosis and management. Pediatr Radiol. 2009;39(4):359-66.

16. Weir K, McMahon S, Taylor S, et al. Oropharyngeal aspiration and silent aspiration in children. Chest. 2011;140(3):589-90.

17. Czinn SJ, Blanchard S. Gastroesophageal reflux disease in neonates and infants: when and how to treat. Pediatr Drugs. 2013;15(1):19-27.

\section{Publisher's Note}

Springer Nature remains neutral with regard to jurisdictional claims in published maps and institutional affiliations.

\section{Submit your manuscript to a SpringerOpen ${ }^{\circ}$ journal and benefit from:}

- Convenient online submission

- Rigorous peer review

- Open access: articles freely available online

- High visibility within the field

- Retaining the copyright to your article

Submit your next manuscript at $\boldsymbol{\nabla}$ springeropen.com 